\title{
ST-Segment Elevation in the Setting of Diabetic Ketoacidosis: Is It Acute Coronary Syndrome?
}

\author{
Jesse Wray ${ }^{1}$, Michael J. Yoo ${ }^{1}$, Rachel E. Bridwell ${ }^{1}$, Lloyd Tannenbaum ${ }^{1}$, Jonathan Henderson ${ }^{2}$
}

1. Emergency Medicine, Brooke Army Medical Center, Fort Sam Houston, USA 2. Emergency Medicine, San Antonio Uniformed Services Health Education Consortium, San Antonio, USA

Corresponding author: Jesse Wray, jpwray91@gmail.com

\begin{abstract}
Diabetic ketoacidosis (DKA) with resulting hyperkalemia can lead to ST-segment elevations on electrocardiogram (ECG). Previous publications theorize that significant improvements in patient potassium levels lead to the resolution of this rare phenomenon, also known as "pseudo-infarct" pattern. The authors provide a unique case along with a literature review of DKA-associated ST-segment elevations. This specific case distinctively demonstrates the resolution of the pseudo-infarct pattern in the setting of minor improvements in serum potassium and continued acidosis.
\end{abstract}

Categories: Cardiology, Endocrinology/Diabetes/Metabolism, Emergency Medicine

Keywords: diabetic ketoacidosis, st-segment elevation, hyperkalemia, pseudo-infarct pattern

\section{Introduction}

Diabetic ketoacidosis (DKA) is one of the most serious complications of diabetes mellitus, characterized by hyperglycemia, metabolic acidosis, ketonemia, and electrolyte abnormalities such as hyperkalemia [1]. Classically, hyperkalemia-related electrocardiogram (ECG) changes include PR interval prolongation, peaked T-waves, widening of the QRS complex, and a sine-wave pattern at severely elevated levels [2]. Less commonly, hyperkalemia can lead to ST-segment elevation, especially in the setting of DKA, though the exact etiology of this injury pattern is likely multifactorial [3-4]. Previous case reports document resolution of this injury pattern with the correction of hyperkalemia. The following case demonstrates evolving STsegment elevations in a patient with DKA that resolved with only minor improvements in his serum potassium. In contrast, previous publications suggest more significant corrections are necessary for STsegment elevation resolution.

Received 03/13/2020 Review began 03/20/2020 Review ended 03/21/2020 Published 03/25/2020

๑) Copyright 2020 Wray et al. This is an open access article distributed under the terms of the Creative Commons Attribution License CC-BY 4.0., which permits unrestricted use, distribution, and reproduction in any medium, provided the original author and source are credited.

\section{Case Presentation}

A 19-year-old male with a past medical history of type 1 diabetes mellitus presented to the emergency department (ED) with one day of nausea, vomiting, and abdominal pain. On arrival to the ED, the patient's vital signs were: temperature of $37^{\circ} \mathrm{C}$, heart rate of 126 beats per minute, blood pressure of $122 / 55 \mathrm{mmHg}$, respiratory rate of 40 breaths per minute, and pulse oximetry of $100 \%$ on room air. On review of systems, he described nausea, diffuse back pain, and generalized abdominal pain but denied polyuria, polydipsia, or recent weight loss. Physical exam revealed a diffusely tender abdomen without rebound or guarding and diffuse back tenderness without gross deformities or evidence of trauma.

Serum studies demonstrated a pH of 7.09, bicarbonate of $9.7 \mathrm{mmol} / \mathrm{L}$, anion gap of 27, potassium of 5.7 $\mathrm{mEq} / \mathrm{L}$, glucose that exceeded the laboratory's maximum measurable value of 700 , and an undetectable troponin. An ECG obtained on arrival demonstrated $3 \mathrm{~mm}$ of ST-segment elevation in V1, $5 \mathrm{~mm}$ of STsegment elevation in V2, and sinus tachycardia to 127 (Figure 1). Intravenous access (IV) was established, and the patient received a $1 \mathrm{~L}$ bolus of lactated ringer's solution and was started on a regular insulin drip at $0.1 \mathrm{U} / \mathrm{kg} / \mathrm{h}$ with no initial bolus. 


\section{Cureus}

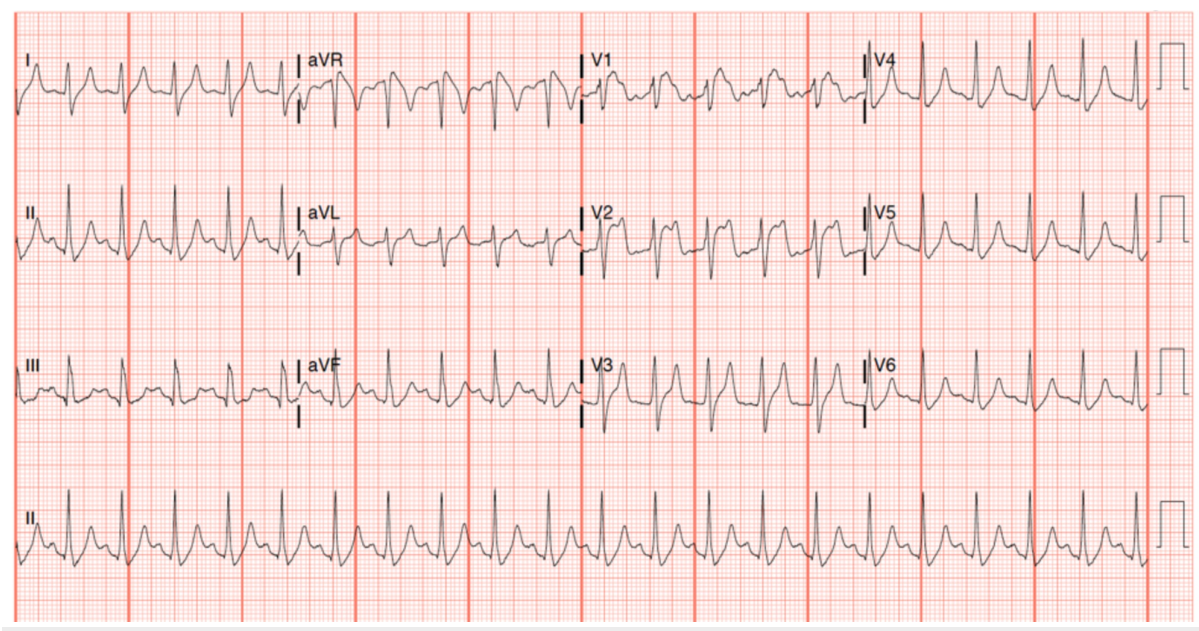

FIGURE 1: Initial electrocardiogram obtained upon arrival to the emergency department demonstrating ST-segment elevation in leads V1 and V2

A repeat ECG obtained 30 minutes later demonstrated interval progression of the ST-segment elevations in V1, V2, and V3 (Figure 2). Based on these dynamic changes, cardiology recommended cardiac catheterization which revealed normal coronary arteries with TIMI (Thrombolysis in myocardial infarction) III flow as well as no evidence of coronary artery dissection or vasospasm. A post-catheterization ECG demonstrated a complete normalization of the ST-segments (Figure 3). Repeat laboratory testing upon completion of his catheterization resulted in a pH of 7.09 , glucose of $619 \mathrm{mg} / \mathrm{dL}$, and potassium of 5.34 $\mathrm{mEq} / \mathrm{L}$. The troponin level following cardiac catheterization became detectable with a peak level of 0.098 , consistent with a type IV myocardial infarction [5]. The patient was admitted to the medical intensive care unit (MICU) and discharged 3 days later with an uncomplicated hospital course.

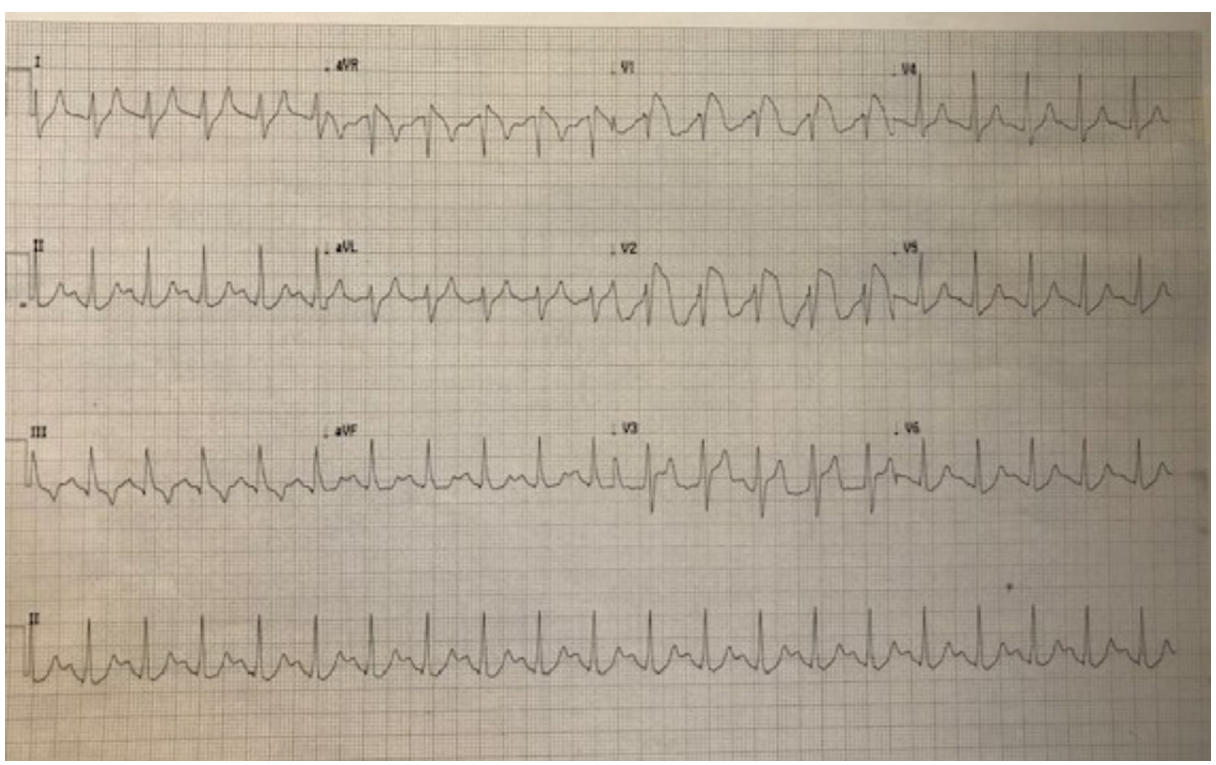

FIGURE 2: Increasing ST-segment elevations in leads V1 and V2; new ST-segment elevations in lead V3 


\section{Cureus}

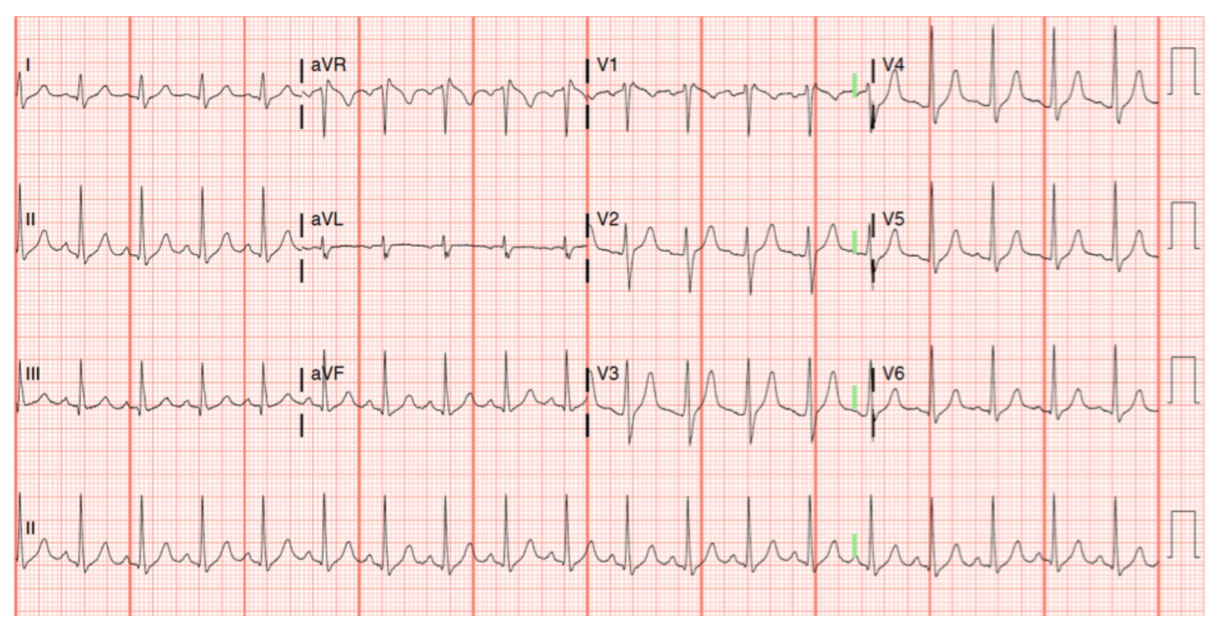

FIGURE 3: Post-catheterization electrocardiogram with resolution of the ST-segment elevations

\section{Discussion}

Hyperkalemia-associated ST-segment elevations in the setting of DKA is a known but rare phenomenon. A literature review identified 19 documented cases of these events (Table 1) [1-4,6-20]. In all cases with documented delta potassium, ST-segment elevations resolved with potassium correction and continued treatment of DKA. During the initial ST-segment elevations, the mean potassium was $7.47 \mathrm{mEq} / \mathrm{L}$ (standard deviation $[\mathrm{SD}]=1.2$ ), and the mean $\mathrm{pH}$ was $7.05(\mathrm{SD}=0.13$ ). At the time of ST-segment normalization, the mean serum potassium was $4.88 \mathrm{mEq} / \mathrm{L}(\mathrm{SD}=0.89)$, and the mean $\mathrm{pH}$ was $7.25(\mathrm{SD}=0.23)$. However, the true value in interpreting this data as a whole is limited given incomplete reporting of data in prior cases. Many of these reports theorize that the resolution of these ECG findings correlated with significant corrections in patient potassium levels [3,6-8,10-11]. This specific case demonstrated normalization of the patient's ECG with clinically insignificant improvement in serum potassium levels. Specifically, this patient's potassium decreased by $6.3 \%(5.7 \mathrm{mEq} / \mathrm{L}$ to $5.34 \mathrm{mEq} / \mathrm{L})$ compared to a mean decrease of $34.7 \%$ in prior cases. The laboratory-specific margin of error for serum potassium was reported to be $0.1 \mathrm{mEq} / \mathrm{L}$ which shows that this change in potassium was essentially negligible. Additionally, the rapid, dynamic changes in this patient's ECG have not been previously described. Prior case reports discuss DKA-associated metabolic acidosis may also contribute to ST-segment elevation [2-4]. However, our case did not have significant changes in $\mathrm{pH}$, serum bicarbonate, or other serum electrolytes with ECG normalization. The exact etiology of the STsegment elevations, in this case, remains likely multifactorial, and further research is needed to better clarify this phenomenon. Given the lack of coronary artery disease noted on angiography, the coved STsegment elevations were likely secondary to the known metabolic derangements associated with DKA. However, the authors theorize that even minor improvements in patient potassium levels may lead to normalization of ST-segment changes on ECG. 


\begin{tabular}{|c|c|c|c|c|c|c|c|c|c|c|}
\hline Case & Age & Sex & Initial K+ & Initial pH & Initial glucose & End $\mathrm{K}+$ & End pH & End glucose & Delta K+ & Delta pH \\
\hline Sharma [6] & 43 & $\mathrm{M}$ & 8.1 & 7.23 & 786 & NR & NR & NR & NA & NA \\
\hline Bellazzini [7] & 40 & $\mathrm{M}$ & 8.3 & 7.01 & 1818 & 7.3 & NR & NR & 1 & NA \\
\hline Sweterlitsch [3] & 46 & $M$ & 7.9 & 6.97 & 1586 & 3.8 & 7.12 & 858 & 4.1 & 0.15 \\
\hline Ziakas [8] & 33 & $\mathrm{~F}$ & 7.2 & 7.16 & High & 4.9 & NR & 255 & 2.3 & NA \\
\hline Wang [9] & 38 & $M$ & 7.9 & 7.21 & 839 & 5.1 & NR & NR & 2.8 & NA \\
\hline Aksakal [4] & 58 & M & 4.4 & 7.15 & 712 & NR & 7.34 & 263 & NA & 0.19 \\
\hline Moulik [10] & 42 & M & 8.9 & 7.06 & High & 4.7 & NR & NR & 4.2 & NA \\
\hline Cohen [2] & 38 & $\mathrm{M}$ & 7.5 & 6.94 & 1206 & 3.8 & 7.43 & 350 & 3.7 & 0.49 \\
\hline Simon [11] & 59 & $\mathrm{M}$ & 8.1 & 7.06 & 1644 & 5.4 & $\mathrm{NR}$ & $\mathrm{NR}$ & 2.7 & NA \\
\hline Carrizales-Sepúlveda [1] & 48 & $\mathrm{M}$ & 5.7 & 6.94 & 620 & NR & NR & NR & NA & NA \\
\hline Egred [12] & 30 & $\mathrm{M}$ & 6.9 & NR & NR & NR & NR & NR & NA & NA \\
\hline Ruiz-Morales [13] & 47 & $\mathrm{~F}$ & 6.7 & NR & 985 & 4.6 & NR & 613 & 2.1 & NA \\
\hline Sims [14] & 20 & $\mathrm{M}$ & 9.4 & 6.92 & 1240 & 5.7 & NR & NR & 3.7 & NA \\
\hline Chawla [15] & 48 & M & 8.3 & 7.09 & 840 & 4 & 7.44 & 452 & 4.3 & 0.35 \\
\hline $\operatorname{Lim}[16]$ & 59 & $\mathrm{~F}$ & 7.2 & 6.74 & 1020 & 4.8 & 6.9 & 792 & 2.4 & 0.16 \\
\hline Kamimura [17] & 45 & $\mathrm{M}$ & 7.3 & 7.01 & 1827 & 5.1 & NR & NR & 2.2 & NA \\
\hline Johnson [18] & 48 & $\mathrm{M}$ & 5.8 & 7.17 & 750 & NR & NR & NR & NA & NA \\
\hline Gelzayd [19] & 42 & $\mathrm{M}$ & 8.7 & NR & 1240 & 4.4 & NR & NR & 4.3 & NA \\
\hline Tatli [20] & 20 & $M$ & 7.7 & 7.1 & 740 & 4.7 & NR & NR & 3 & NA \\
\hline
\end{tabular}

TABLE 1: Summary of previously published pseudo-infarct pattern electrocardiograms in the setting of diabetic ketoacidosis associated hyperkalemia.

Initial and subsequent potassium, pH, and glucose levels are given. Abbreviations: $\mathrm{M}=$ Male, F = Female, $\mathrm{K}+=$ Potassium, NR = Not Reported, NA $=$ Not Available.

\section{Conclusions}

Emergency physicians are faced with diagnostic dilemmas on a frequent basis. One such conundrum is ruling out myocardial infarction in the setting of DKA. The above case and associated literature review highlight the diagnostic obfuscation from metabolic derangements associated with DKA mimicking injury pattern on ECG. Clinicians must continue to recognize that myocardial infarction is a known precipitant of DKA, and these two pathologies can coexist. However, this case report and literature review reinforce that DKA can be associated with ECG manifestations mimicking acute myocardial ischemia. Emergency medicine providers should be aware of this phenomenon in order to attempt to differentiate it from an ST-segment elevation myocardial infarction.

\section{Additional Information Disclosures}

Human subjects: Consent was obtained by all participants in this study. Conflicts of interest: In compliance with the ICMJE uniform disclosure form, all authors declare the following: Payment/services info: All authors have declared that no financial support was received from any organization for the submitted work. Financial relationships: All authors have declared that they have no financial relationships at present or within the previous three years with any organizations that might have an interest in the submitted work. Other relationships: All authors have declared that there are no other relationships or activities that could appear to have influenced the submitted work.

\section{References}


1. Carrizales-Sepúlveda EF, Del Cueto-Aguilera ÁN, Jiménez-Castillo RA, et al.: Pseudomyocardial infarction in a patient with severe diabetic ketoacidosis and mild hyperkalemia. Case Rep Cardiol. 2019, 2019:1-4. 10.1155/2019/4063670

2. Cohen A, Utarnachitt RV: Electrocardiographic changes in a patients with hyperkalemia and diabetic acidosis associated with acute anteroseptal pseudomyocardial infarction and bifascicular block. Angiology. 1981, 32:361-364. 10.1177/000331978103200510

3. Sweterlitsch EM, Murphy GW: Acute electrocardiographic pseudoinfarction pattern in the setting of diabetic ketoacidosis and severe hyperkalemia. Am Heart J. 1996, 132:1086-1089. 10.1016/s00028703(96)90037-x

4. Aksakal E, Duman H, Ulus T, Bayram E: Acute inferior pseudoinfarction pattern in a patient with normokalemia and diabetic ketoacidosis. Am J Emerg Med. 2009, 27:251-253. 10.1016/j.ajem.2008.06.024

5. Reddy K, Khaliq A, Henning RJ: Recent advances in the diagnosis and treatment of acute myocardial infarction. World J Cardiol. 2015, 7:243-276. 10.4330/wjc.v7.i5.243

6. Sharma E, Dahal S, Sharma P, Ghimire DK, Dahal S: A case of pseudoinfarction pattern in diabetic ketoacidosis: a diagnostic and therapeutic dilemma. Cardiol Res. 2018, 9:250-252. 10.14740/cr747w

7. Bellazzini MA, Meyer T: Pseudo-myocardial infarction in diabetic ketoacidosis with hyperkalemia. J Emerg Med. 2010, 39:139-141. 10.1016/j.jemermed.2007.04.024

8. Ziakas A, Basagiannis C, Stiliadis I: Pseudoinfarction pattern in a patient with hyperkalemia, diabetic ketoacidosis and normal coronary vessels: a case report. J Med Case Rep. 2010, 4:115. 10.1186/1752-1947-4115

9. Wang K: "Pseudoinfarction" pattern due to hyperkalemia. N Engl J Med. 2004, 351:593. 10.1056/NEJMicm970566

10. Moulik PK, Nethaji C, Khaleeli AA: Misleading electrocardiographic results in patient with hyperkalaemia and diabetic ketoacidosis. BMJ. 2002, 325:1346. 10.1136/bmj.325.7376.1346

11. Simon BC: Pseudomyocardial infarction and hyperkalemia: a case report and subject review . J Emerg Med. 6:511-515. 10.1016/0736-4679(88)90410-6

12. Egred M, Morrison WL: Diabetic keto-acidosis and hyperkalaemia induced pseudo-myocardial infarction . Heart. 2005, 91:1180. 10.1136/hrt.2004.056663

13. Ruiz-Morales J, Canha C, Al-Saffar F, Ibrahim S: Anterior myocardial pseudoinfarction in a patient with diabetic ketoacidosis. J Geriatr Cardiol. 2018, 15:238-240. 10.11909/j.issn.1671-5411.2018.03.007

14. Sims DB, Sperling LS: ST-segment elevation resulting from hyperkalemia. Circulation. 2005, 111:295-6. 10.1161/01.CIR.0000165127.41028.D1

15. Chawla KK, Cruz J, Kramer NE, Towne WD: Electrocardiographic changes simulating acute myocardial infarction caused by hyperkalemia: report of a patient with normal coronary arteriograms. Am Heart J. 1978, 95:637-640. 10.1016/0002-8703(78)90306-X

16. Lim YH, Anantharaman V: Pseudo myocardial infarct--electrocardiographic pattern in a patient with diabetic ketoacidosis. Singapore Med J. 1998, 39:504-506.

17. Kamimura M, Hancock EW: Acute MI pattern in diabetic ketoacidosis. Hosp Pract (Off Ed). 1992, 27:28-30. 10.1080/21548331.1992.11705534

18. Johnson CD: Electrocardiogram of the month: pseudo-acute myocardial infarction. Bol Asoc Med P R. 1983, 75:288-289.

19. Gelzayd E, Holzman D: Electrocardiographic changes of hyperkalemia simulating acute myocardial infarction: report of a case. Dis Chest. 1967, 51:211-212. 10.1378/chest.51.2.211

20. Tatli E, Altun A, Yilmaztepe M: ST segment elevation following sinoventricular rhythm in a patient with diabetic ketoacidosis. Cardiol J. 2007, 14:497-499. 